\title{
Performance of the DBS Satellite Receiver under the Impact of Rainfall and Terrestrial Interference
}

\author{
Zaid Ahmed Shamsan $(\mathbb{D})^{1,2}$ and Ahmed Al-Saman $\mathbb{D D}^{3}$ \\ ${ }^{1}$ College of Engineering, Electrical Eng. Department, Imam Mohammad Ibn Saud Islamic University, Riyadh, Saudi Arabia \\ ${ }^{2}$ Faculty of Engineering and Information Technology, Taiz University, Taiz, Yemen \\ ${ }^{3}$ Department of Manufacturing and Civil Engineering, Norwegian University of Science and Technology, 2815 Gjøvik, Norway
}

Correspondence should be addressed to Zaid Ahmed Shamsan; shamsan22@gmail.com

Received 23 February 2021; Revised 2 August 2021; Accepted 25 August 2021; Published 8 September 2021

Academic Editor: Michael McGuire

Copyright (c) 2021 Zaid Ahmed Shamsan and Ahmed Al-Saman. This is an open access article distributed under the Creative Commons Attribution License, which permits unrestricted use, distribution, and reproduction in any medium, provided the original work is properly cited.

\begin{abstract}
This article presents a new study on the feasibility of operating a direct broadcasting satellite (DBS) system under the effect of both precipitation and interference from a fixed service (FS) at K-band in a semiarid region. The carrier-to-noise plus interference ratio (CNIR) as a protection criterion has been adopted to make sure that the receiver of the DBS system operates with an acceptable performance under rainfall and interference from FS. Various measured data for rainfall in different areas have been utilized to investigate different rain rate exceedance percentages. Results have been shown that areas with high rain rates have a small CNIR at the DBS receiver and require large protection distances compared to low-rain rate areas and vice versa. Some mitigation techniques have been suggested to alleviate the effect of rain and terrestrial interference on the DBS receiver performance.
\end{abstract}

\section{Introduction}

The overcrowding in lower spectrum frequency bands like Cband and $\mathrm{Ku}$-band is predictable to lead new systems to move gradually more to $\mathrm{K}$-band and, in a longer-term, to higher bands $[1,2]$ such as in the $5 \mathrm{G}$ and $6 \mathrm{G}$ generation systems. Thus, frequency bands higher than $6 \mathrm{GHz}$ will be highly significant in future systems related to Earth-space connection. In those bands, attenuation due to rain represents a dominant factor that reduces the system availability and negatively affects its performance especially in heavy rain areas such as in south Saudi Arabia. Thus, the rain attenuation impacts higher frequency bands and it is more harmful than that in the lower bands $[3,4]$. According to ITU-R, the $21.4-22 \mathrm{GHz}$ band has been allocated to 3 dissimilar services: fixed, mobile, and satellite broadcasting services in the $1^{\text {st }}$ and $3^{\text {rd }}$ regions including Saudi Arabia which is considered as a semiarid area. Therefore, the cochannel interference is certain, which may affect the performance of the direct broadcasting satellite (DBS) system receiver. As a result, the satellite communication system must be designed to be reliable against interference from terrestrial systems [5]. The interference can be estimated concerning the receiving system criteria of the carrier-to-noise plus interference ratio (CNIR) [6]. The Saudi Communications and Information Technology Commission (CITC) proposed to use the 21.4$22 \mathrm{GHz}$ for both the DBS system and fixed service (FS) [7]; thus, this paper will consider the cochannel interference from FS to the DBS system as well as the rain attenuation effect with various rain rate exceedance to investigate the effect of these factors on the DBS system receiver performance and then to determine the feasibility of the concurrent operation of the DBS system receiver and FS service.

The paper is organized as follows. Relevant prior work and contribution are discussed in Section 2. Criteria of dissimilar system coordination are presented in Section 3. In Sections 4 and 5, the rain distribution, methodology, and proposed scenarios are explained in detail. The criterion of the CNIR and communication link simulation are provided in Section 6. Assumptions, results, and discussion of the 
obtained results are recorded in Section 7. In Section 8, remarkable conclusions have been drawn.

\section{Relevant Prior Work and Contribution}

A number of publications reported the research in the field of concurrently operating the terrestrial fixed service (FS) with satellite services (SS) (broadcasting (BSS) and fixed (FSS)), in different spectrum frequency bands [4, 7-18]. Most researches mainly study the performance of satellite receiver affected by the FS system based on spectrum sharing policies between the dissimilar systems. These articles essentially focus on the impact of interference, rainfall, shared system parameters, and its impacts on sharing performance. The paper characteristics and the significant remarks are summarized in Table 1. In addition, for the purpose of this paper, the publications regarding the simultaneously operating of the satellite service and FS can be divided into two categories: (i) under a clear sky and (ii) under rain condition.

In $[9,10,12,17,18]$, the clear sky condition was considered at the operating frequency bands for the two systems that are less than $6 \mathrm{GHz}$ (C-band and L-band), while various studies were carried out on higher frequency bands within $(17.3-19.7 \mathrm{GHz})[11,13-16]$. All these studies discussed the interference impact on the satellite service from the FS system.

On the other hand, the studies which have considered the impact of rain on operating of the satellite service and FS were reported in $[1,4,7]$ which have been carried out in frequencies higher than $10 \mathrm{GHz}$. The frequencies above $10 \mathrm{GHz}$ are influenced by rain attenuation while the lower frequencies than $6 \mathrm{GHz}$ are not seriously affected by rain attenuation. These studies investigated both impact of the rain attenuation and the interference from the FS on the satellite services.

In terms of the interference protection criterion, most studies depend on the INR, CNIR, and then the CIR ratio whereas some studies depend on the maximum tolerable interference or combine more than one of these criteria.

In terms of rainfall intensity, it can be seen that the study in [8] discusses the intersystem interference in Greece as a Mediterranean region, while the research in [4] investigated the spectrum sharing operation of the satellite and FS services in the tropical region as a heavy rain area. Moreover, the work in [7] studied the satellite and FS services in the semiarid conditions.

Comparing to the previous literature, this paper considers the semiarid area but for various rainfall exceedance probabilities, a stricter interference protection criterion, and various off-axis angles between the DBS receiver and the FS service. The contribution of this paper can be summarized in at least three points, as follows:

(a) In the current paper, the thermal noise of the DBS receiver has been taken into account, so this study uses the carrier-to-noise plus interference ratio (CNIR) criteria, while in [7], the criterion was different, carrierto-interference ratio (CIR), as the receiver noise in
[7] was not considered. This makes the current paper more technically sound

(b) The CIR criterion value in [7] is $23 \mathrm{~dB}$, while this study uses a CNIR of $4.7 \mathrm{~dB}$ which adds more restrictions on the receiver ability to pick up the satellite signal

(c) The study in [4] uses the rain attenuation link budget and the research in [7] applies the rain rate exceedance of $0.01 \%$ which does not always occur. Here, various situations of precipitation unavailability percentages (various rain rate exceedance probabilities) which have a high probability to happen especially in the semiarid regions are used. The rain rate exceedances that have been considered in this study are $0.001 \%, 0.01 \%, 0.016 \%$, and $0.25 \%$

\section{System Protection Criteria}

Several criteria can be used to evaluate the feasibility of a system to work in an interference environment to make sure that the system is protected from interference. These criteria are shown in Figure 1. As can be seen in Figure 1, the protection criteria include carrier-to-interference ratio (CIR) and interference-to-noise ratio (INR) which can be defined as a relative or absolute level of interfering signal power determined at the input of the victim receiver, under certain situations, such that the tolerable performance deterioration is not allowed $[5,6]$. For acceptable system performance, the necessary CIR is greater than $23 \mathrm{~dB}[7,19]$ and $-10 \mathrm{~dB}$ for INR [20]. Also, the term carrier-to-noise ratio (CNR) refers to the ratio of signal power to noise power at the receiver output [21]. A CNR > $10 \mathrm{~dB}$ is agreed to be a standard value. On the other hand, the nature of the CNIR is due to the impact of the receiver antenna noise added to the interference signal. The CNIR is a significant criterion contributing to the much appropriate precise estimation of the entire outage period of satellite link that suffers from interference lacking any condition concerning the thermal noise. This is an unavoidable condition specifically for systems operating within an interference environment as a dominant factor $[21,22]$. In [22], it is stated that the necessary CNIR is $4.7 \mathrm{~dB}$ for DBS to operate with satisfactory performance. As a result of both the interference $(I)$ from the FS and the receiver thermal noise power $(N)$ of the DBS receiver, the CNIR ( $d B)$ can be estimated by equation $(1)[23,24]$ as follows:

$$
\frac{C}{(N+I)}=-10 \log \left(10^{-0.1(C / N)}+10^{-0.1(C / I)}\right)
$$

where $C$ is the carrier power of the satellite transmitter at the DBS receiver.

As can be seen from the literature work in Section 2, all performance metrics are previously used for spectrum sharing studies. The CNIR is a significant measure performance, and in this paper, the sharing performance criteria of the CNIR are selected due to the following characteristics: 
TABLE 1: Relevant prior work summarizing.

\begin{tabular}{|c|c|c|c|c|c|}
\hline Ref. & $\begin{array}{l}\text { Frequency } \\
\text { band }\end{array}$ & Weather condition & Sharing criteria & $\begin{array}{l}\text { Shared } \\
\text { systems }\end{array}$ & Remarks \\
\hline$[8]$ & $>10 \mathrm{GHz}$ & $\begin{array}{l}\text { Rainy (Mediterranean } \\
\text { region) }\end{array}$ & CNIR & BSS and FS & $\begin{array}{l}\text { It presents a model for CNIR prediction of a BSS } \\
\text { downlink interfered by an adjacent FS. It focuses on } \\
\text { the additional outage time caused by rain fading on } \\
\text { the wanted satellite slant path and the interfering } \\
\text { terrestrial path. }\end{array}$ \\
\hline [9] & $3.8 \mathrm{GHz}$ & Clear sky & INR & $5 \mathrm{G}$ and $\mathrm{FSS}$ & $\begin{array}{l}\text { It estimates the protection distance to satisfy the } \\
\text { protection criterion between the FSS and the } 5 \mathrm{G} \\
\text { system with relation to elevation angle and antenna } \\
\text { pattern. }\end{array}$ \\
\hline$[10]$ & $\begin{array}{c}3.4- \\
4.2 \mathrm{GHz}\end{array}$ & Clear sky & $\begin{array}{l}\text { INR and the } \\
\text { maximum } \\
\text { tolerable } \\
\text { interference }\end{array}$ & $5 \mathrm{G}$ and FSS & $\begin{array}{l}\text { It presents the impact of out-of-band emissions and } \\
\text { potential low-noise block (LNB) saturation at the FSS } \\
\text { Earth station receiver and the consequences of the } \\
\text { deployment of active antenna systems in the terrestrial } \\
\text { FS. }\end{array}$ \\
\hline$[11]$ & $\begin{array}{c}17.7- \\
19.7 \mathrm{GHz}\end{array}$ & Clear sky & INR & FSS and FS & $\begin{array}{l}\text { Various sensing and avoidance schemes have been } \\
\text { proposed for allowing the coexistence of FSS downlink } \\
\text { with the terrestrial FS links. }\end{array}$ \\
\hline$[12]$ & $3.5 \mathrm{GHz}$ & Clear sky & INR & $\begin{array}{l}\text { FSS and small } \\
\text { cell FS }\end{array}$ & $\begin{array}{l}\text { It estimates the protection distances required to } \\
\text { protect FSS Earth stations from the FS for the case } \\
\text { when small cells are deployed indoor and outdoor. }\end{array}$ \\
\hline$[13]$ & $\begin{array}{c}17.7- \\
19.7 \mathrm{GHz}\end{array}$ & Clear sky & CNIR & $\begin{array}{c}\text { FSS and (BSS } \\
\text { and FS) }\end{array}$ & $\begin{array}{l}\text { Spectrum databases for BSS and FS systems have been } \\
\text { used to estimate CNIR based on a cognitive basis to } \\
\text { increase the overall throughput. }\end{array}$ \\
\hline$[14]$ & $\begin{array}{l}17.3 \text { to } \\
17.7 \mathrm{GHz}\end{array}$ & Clear sky & $\begin{array}{l}\text { The maximum } \\
\text { tolerable } \\
\text { interference }\end{array}$ & $\begin{array}{l}\text { FSS and (FS } \\
\text { and BSS) }\end{array}$ & $\begin{array}{c}\text { Interference from BSS and FS is estimated using real } \\
\text { databases and propagation models using correct } \\
\text { terrain profiles. Some operational challenges are also } \\
\text { discussed. }\end{array}$ \\
\hline [15] & $\begin{array}{c}18.8- \\
19.7 \mathrm{GHz}\end{array}$ & Clear sky & INR & $\begin{array}{l}\text { GSO network } \\
\text { and terrestrial } \\
\text { network }\end{array}$ & $\begin{array}{l}\text { It estimates the minimum separation distances } \\
\text { between the geostationary satellite Earth station and } \\
\text { the terrestrial FS in the worst case. }\end{array}$ \\
\hline [16] & $\begin{array}{c}17.3- \\
18.4 \mathrm{GHz}\end{array}$ & Clear sky & INR & FSS and BSS & $\begin{array}{l}\text { It studies the effect of the elevation angle on the } \\
\text { sharing between the BSS and FSS Earth stations with/ } \\
\text { without shielding in FSS/BSS terminals. The sharing is } \\
\text { highly feasible with proper protection zones around } \\
\text { stations. }\end{array}$ \\
\hline [17] & $2.185 \mathrm{GHz}$ & Clear sky & CIR & MSS and MS & $\begin{array}{l}\text { It estimates sharing between the mobile satellite } \\
\text { service (MSS) system and the mobile service (MS) } \\
\text { system. Sharing is hardly feasible in a cochannel } \\
\text { frequency and colocated situations. }\end{array}$ \\
\hline$[18]$ & $\begin{array}{c}3.4- \\
4.2 \mathrm{GHz}\end{array}$ & Clear sky & INR & $\begin{array}{l}\text { FSS NWs and } \\
\text { IMT2000 }\end{array}$ & $\begin{array}{l}\text { It investigates the sharing between the FSS networks } \\
\text { (with low and high density of deployment) and IMT } \\
2000 \text {. }\end{array}$ \\
\hline [4] & $\begin{array}{c}21.4- \\
22 \mathrm{GHz}\end{array}$ & Rainy (tropical region) & CNIR and INR & DBS and FS & $\begin{array}{l}\text { It investigates the sharing between the DBS and FS } \\
\text { services with the rain attenuation link budget. It is } \\
\text { found that the denser the clutter area, the lower the } \\
\text { interference introduced to the wanted system. }\end{array}$ \\
\hline [7] & $\begin{array}{c}21.4- \\
22 \mathrm{GHz}\end{array}$ & Rainy (semiarid region) & CIR & DBS and FS & $\begin{array}{l}\text { It investigates the sharing between the DBS and FS } \\
\text { services for rain rate exceedance of } 0.01 \% \text { only. The } \\
\text { protection distance between the systems can be } \\
\text { affected by changing the height of DBS ES. }\end{array}$ \\
\hline $\begin{array}{l}\text { This } \\
\text { paper }\end{array}$ & $\begin{array}{c}21.4- \\
22 \mathrm{GHz}\end{array}$ & $\begin{array}{l}\text { Rainy (semi-arid region) } \\
\text { various rain rate } \\
\text { exceedance probabilities }\end{array}$ & CNIR & DBS and FS & $\begin{array}{c}\text { It investigates the sharing between the DBS and FS } \\
\text { services with various precipitation unavailability } \\
\text { percentages which have high probabilities to happen } \\
\text { especially in the semiarid regions. Various off-axis } \\
\text { angles are employed. }\end{array}$ \\
\hline
\end{tabular}




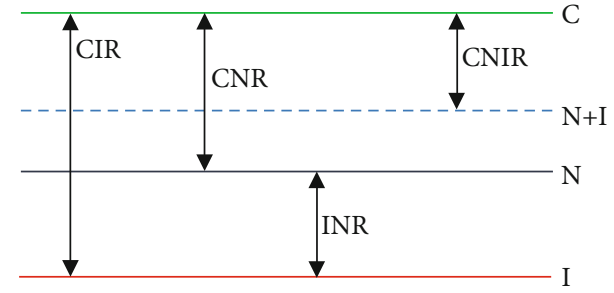

Figure 1: Protection criteria levels at communication receivers.

(a) Indicating equation (1), it can be seen that the CNIR depends on the CNR and CIR ratios. In addition, CIR in turn depends also on the INR ratio [8]: $C / I$ $(\mathrm{dB})=C / N(\mathrm{~dB})-I / N(\mathrm{~dB})$ this means that the CNIR criteria implicitly include all performance metrics

(b) The CNIR has been used in many studies, such as [25] which concluded that at the frequency bands $(\mathrm{Ku}, \mathrm{K}$, and $\mathrm{Ku})$, the interference problem of adjacent satellites, essentially clear for spotbeam/cell edge terminals, becomes more exacerbated by propagation effects, mainly attenuation by rain. In addition, the CNIR is of supreme significance in the design of new satellite broadband systems based on digital video broadcasting (DVB)

(c) In cellular systems for example [26], the probability distribution of the CNIR has a significant task in performance evaluation of the system, managing of the radio resource, and planning of the radio network. Thus, a precise probability density function (PDF) of CNIR leads to effortlessly predicting of the capacity and coverage of the system; otherwise, time-consuming and sophisticated simulations should be used

(d) Generally, recent development of multiple input multiple output (MIMO) beamforming techniques creates a new dimension for cochannel users to coexist without causing severe interference to each other. In conventional methods, beamforming is obtained by either maximizing the carrier-to-interference plus noise ratio (CNIR) or minimizing the transmission energy subject to a minimum CNIR constraint $[27-30]$

\section{Rain Distribution}

A lot of rain effect studies have been conducted in different frequency bands such as in [31-34] in a tropical region. The Kingdom of Saudi Arabia map is distributed into five climate regions which can be described as a semiarid region. Therefore, the available measured instantaneous rain rate distributions were pooled for each of the climate regions $[2,35]$. According to Table 2, the findings indicate that the southwestern side of Saudi Arabia has higher rain rates and the north side has lower rainfall rates. Thus, five locations have been selected to classify rain climate regions for
TABLE 2: Measured rainfall rate readings and calculated attenuation for the selected locations.

\begin{tabular}{lccccc}
\hline Climate regions & Tabuk & Riyadh & Makkah & Abha & Al Bahah \\
\hline$R_{0.01}(\mathrm{~mm} / \mathrm{h})$ & 9.71 & 17.17 & 27.92 & 37.24 & 53.10 \\
$A_{0.01}(\mathrm{~dB})$ & 12.07 & 25.478 & 39.6 & 52.74 & 76.6 \\
$R_{0.016}(\mathrm{~mm} / \mathrm{h})$ & 7.65 & 13.53 & 21.85 & 29.27 & 40.47 \\
$A_{0.016}(\mathrm{~dB})$ & 8.758 & 18.32 & 29.114 & 39.13 & 54.94 \\
$R_{0.001}(\mathrm{~mm} / \mathrm{h})$ & 31.20 & 55.09 & 92.74 & 121.07 & 200.95 \\
$A_{0.001}(\mathrm{~dB})$ & 37.408 & 78.13 & 129.59 & 169.583 & 287.58 \\
\hline
\end{tabular}

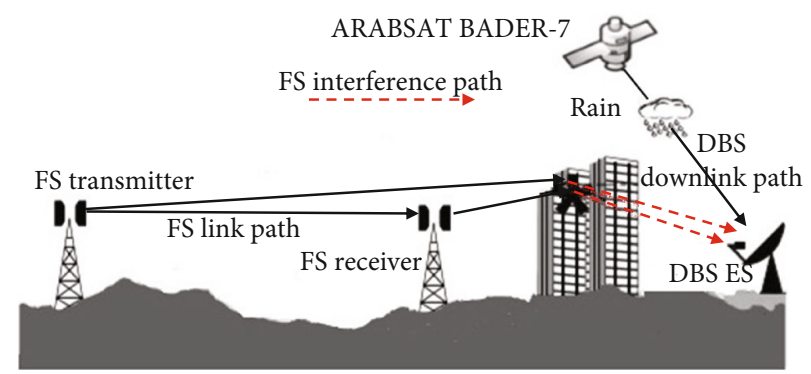

FIGURE 2: The proposed arrangement between an interfered downlink signal (DBS) which suffers from rain and FS interference in different propagation environments.

the Kingdom of Saudi Arabia reliant on weather circumstances which in turn rely upon longitude and latitude locations. These locations are Riyadh in the middle (2), Makkah in the west (3), Abha in the south (4), Al Bahah in the southwest (5), and Tabuk in the north (1). These areas are distributed on diverse sides in Saudi Arabia characterizing different rainfall rates based on weather circumstances and different longitude and latitude. According to ITU-R recommendations, a link availability of $99.99 \%$ was selected to denote the intensity of rainfall $(\mathrm{mm} / \mathrm{h})$ of $0.01 \%$ probability of rain incidence on a specific place serviced by a wireless system. This percentage represents 52.56 minutes/year of outage time.

\section{Methodology and Proposed Scenarios}

As shown in Figure 2, a DBS Earth station (ES) receiver and FS operate in a close area. In this scenario, both systems use the $21.4-22 \mathrm{GHz}$ band, with an identical carrier frequency of $21.728 \mathrm{GHz}$ which can create an imperative interference. It is supposed that an ES receiver of the direct broadcasting service (the desirable link) is deleteriously saturated by the signal from an FS system. The interfering can influence the downlink desired signal in both clear-air and rainfall. Whereas, a $21.728 \mathrm{GHz}$ carrier frequency of the DBS signal (horizontally polarized) is directed from the $26^{\circ} \mathrm{E}$ geostationary orbit ARABSAT BADER-7 into 5 ESs assumed to be situated at the five selected locations in Saudi Arabia. Thus, depending on the specification of two systems, the effect of the interference is certain in clear air and rainfall (worst case). Additionally, the impact of rain attenuation and the receiver antenna noise on the reception quality is evaluated. The simulation is built upon real values related to the DBS 
TABLE 3: The main key spectrum sharing assumptions and parameters $[7,36]$.

\begin{tabular}{|c|c|c|}
\hline \multirow{2}{*}{ Parameters } & \multicolumn{2}{|c|}{ Value } \\
\hline & DBS & FS \\
\hline Carrier frequency $(\mathrm{MHz})$ & & \\
\hline ARABSAT Bader-7 longitude (E ) & 26 & - \\
\hline DBS ES receiver sensitivity (clear sky) (dBW) & -119.566 & - \\
\hline Gain of receiver antenna $(\mathrm{dBi})$ & 56.6557 & 34.8 \\
\hline EIRP ES (dBW) & 34.2 & - \\
\hline Free space path loss $(\mathrm{dB})$ from satellite to earth station & 210.4 & - \\
\hline Saudi Arabia rain height $(\mathrm{m})$ & & \\
\hline Receiver antenna height above mean sea level $(\mathrm{km})$ & 0.1 & 0.15 \\
\hline Bandwidth (MHz) & 11.6580 & 7 \\
\hline Bandwidth of noise $(\mathrm{MHz})$ & 8.6356 & 7 \\
\hline Off-axis angle of antenna $\left({ }^{\circ}\right)$ & 3 & - \\
\hline Diameter of receiver antenna $(\mathrm{m})$ & 3.7 & 0.6 \\
\hline Interferer power of FS (EIRP) (dBW) & - & -146.6 \\
\hline
\end{tabular}

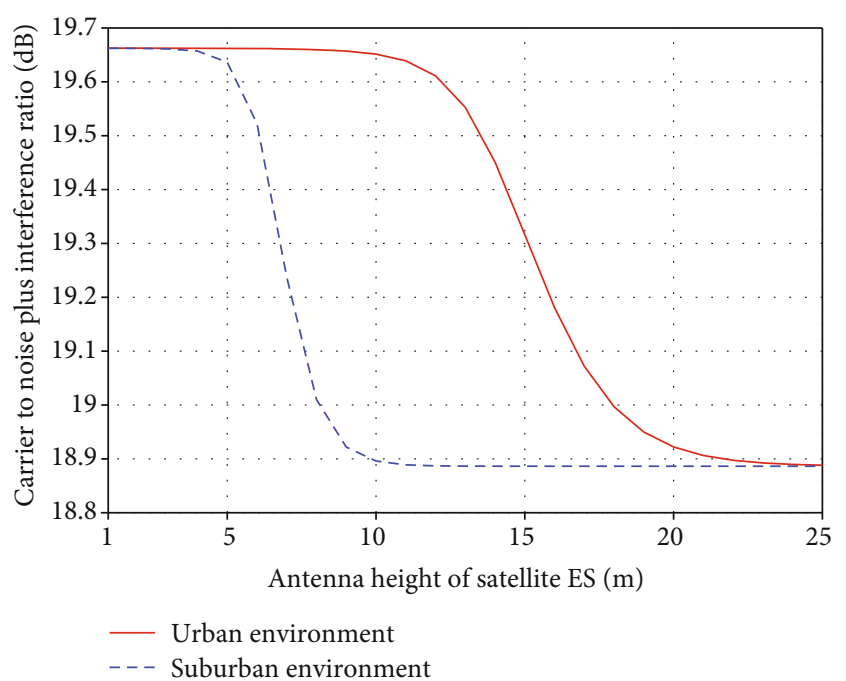

FIGURE 3: The receiver CNIR against the antenna height of the DBS receiver under clear sky condition.

service obtained from the Arab Satellite Communications Organization (ARABSAT), the satellite service provider in Saudi Arabia. Moreover, the five selected locations look to ARABSAT BADER-7 by diverse elevation and azimuth angles and FS parameters are based on [36]. The scenario shown in Figure 2 is applied to the five different selected locations over Saudi Arabia which are shown in Table 2. Further, clutter loss is considered within this scenario which is contributing to limit the interference power (unwanted power) depending on the Earth station antenna height and the nature of the area.

The CNIR level is evaluated in different propagation environments for all selected locations under a clear sky and rain conditions over which two different area categories (urban, suburban). Due to the fact that each area has dissimilar clutter features that can cause a definite loss to the interfering signal [37-40]. The received downlink signal, $P_{r}$ (watt), at the DBS receiver can be evaluated by using equation (2) as follows:

$$
P_{r}=P_{t} G_{t} G_{r}\left(\frac{4 \pi d}{\lambda}\right)^{2},
$$

where $P_{t}$ is the transmission power (watt) from the satellite in the sky, $G_{t}$ is the satellite transmission antenna gain, $G_{r}$ is the antenna gain of the DBS Earth station (DBS receiver), $d$ is the physical path between the DBS receiver and satellite $(\mathrm{km})$, and $\lambda$ is the operating wavelength in $(\mathrm{m})$. The free space loss $L_{f s l}$ given by equation (3) as follows:

$$
L_{f s l}=\left(\frac{4 \pi d}{\lambda}\right)^{2}
$$

Then, the specific attenuation, $\gamma_{R}(\mathrm{~dB} / \mathrm{km})$, is calculated and relied on real measured quantities of rain, $R_{0.01}$ $(\mathrm{mm} / \mathrm{h})$ and values of $k$ and $\alpha$, which are functions of frequency, $f$, and polarization specified in ITUR P.838, as follows [28]:

$$
\gamma_{R}=k\left(R_{0.01}\right)^{\alpha}
$$

The rain attenuation, $A_{0.01}(\mathrm{~dB})$, is given by equation (5) as follows:

$$
A_{0.01}=\gamma_{R} L_{E}
$$

where $L_{E}$ is the effective path length $(\mathrm{km})$.

The local clutter can cause extra losses that affect the interference path since it can block the signal, this loss is denoted by $L_{C}$, and thus, its amount contributes to the entire interference power. This loss is expressed as follows [37] in (6), where $h$ is the antenna height above the local ground 


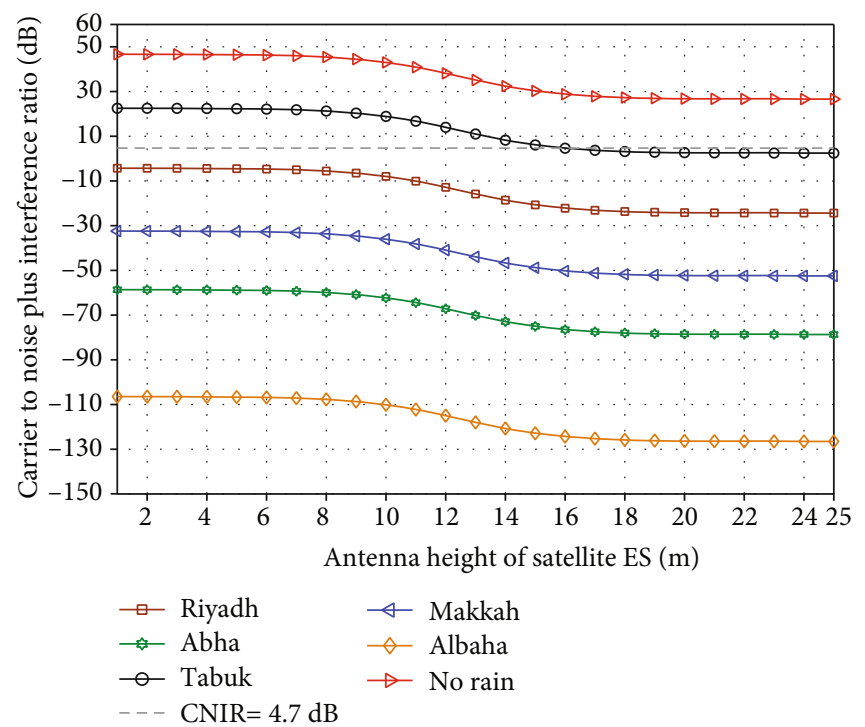

FIgURE 4: The CNIR against ES antenna height (urban area).

level, $h_{a}$ is the nominal clutter height above the local ground level, and $d_{c}$ is the distance from the nominal clutter point to the antenna.

$$
L_{C}=10.25 e^{-d_{c}}\left(1-\tanh \left(6\left(\frac{h}{h_{a}}-0.625\right)\right)\right)-0.33
$$

The nominal distance and nominal clutter height for the urban area are $20 \mathrm{~m}$ and $0.02 \mathrm{~km}$, respectively, whereas theses values for the suburban area are $9 \mathrm{~m}$ and $0.025 \mathrm{~km}$, respectively [4].

\section{CNIR and Communication Link Simulation}

A MATLAB code has been created to simulate the CNIR and the communication links in which the environment of the satellite communication system link has been installed by defining the main connection link parameters that contribute to the computing of the carrier power $(C)$ at the DBS receiver. These parameters include (a) the DBS satellite transmitter, (b) the gain of the DBS receiver (earth station) antenna, and (c) the propagation channel parameter effects which are mainly represented by (i) rain phenomena (by equations (4) and (5)), (ii) clutter loss (by equation (6)), and (iii) free space attenuation loss (by equation (3)). Then, all these parts are integrated into the satellite communication link environment as equation (1), where all factors will contribute to the carrier signal $(C)$ at the DBS receiver as in equation (7), as follows:

$$
C(d B)=P_{r}-A_{0.01}-L_{C}
$$

Next, the effect of the interference link coming from the FS system as well as the noise parameters of the receiver is added together and computed to give the total effect of the interference $(I)$ and thermal noise power $(N)$, which is $N$ $+I$, as in equation (1). Finally, a comparison between the

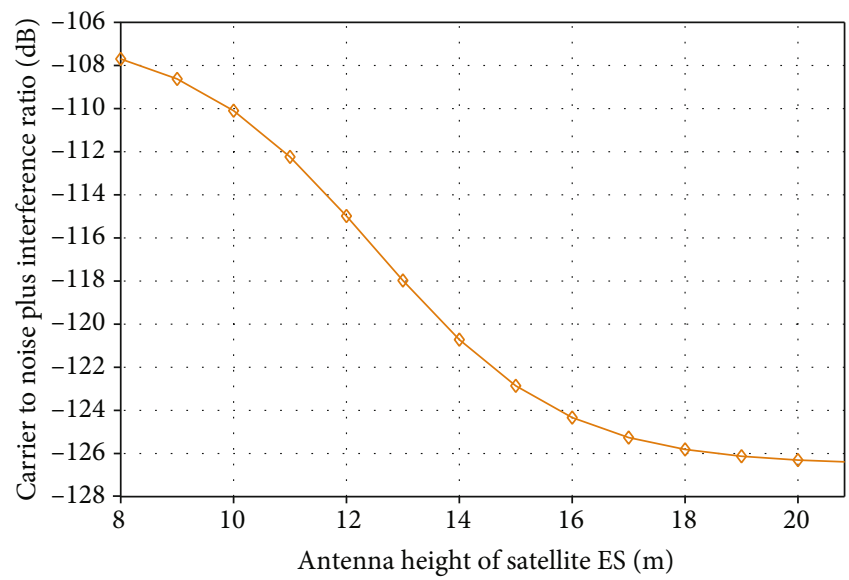

FIgURE 5: Magnification of Figure 4: the CNIR against the ES antenna height in $\mathrm{Al}$ Bahah (urban area).

CNIR resultant from the simulation and the CNIR criterion is made to determine whether the DBS receiver can receive the signal from the satellite with good performance or not.

\section{Assumptions, Results, and Discussion}

Table 3 describes the key factors for the considered systems (DBS ES and FS transmitter). The distances between the FS transmitter and the DBS Earth station receiver are considered as one of the coexistence limitations. Thus, the CNIR was investigated through distances of 1 to $50 \mathrm{~km}$ which can be assumed to be a line-of-sight (LOS) case.

In Figure 3, two deployment areas (urban and suburban) under a clear sky are shown with CNIR criteria in terms of the DBS receiver antenna height. It can be observed that the CNIR has not much difference in the CNIR for both the urban area and the suburban area; that is, changing antenna height by $18 \mathrm{~m}$ height from 4 to $22 \mathrm{~m}$ makes only a difference in a CNIR of $1 \mathrm{~dB}$. Therefore, we can say that 


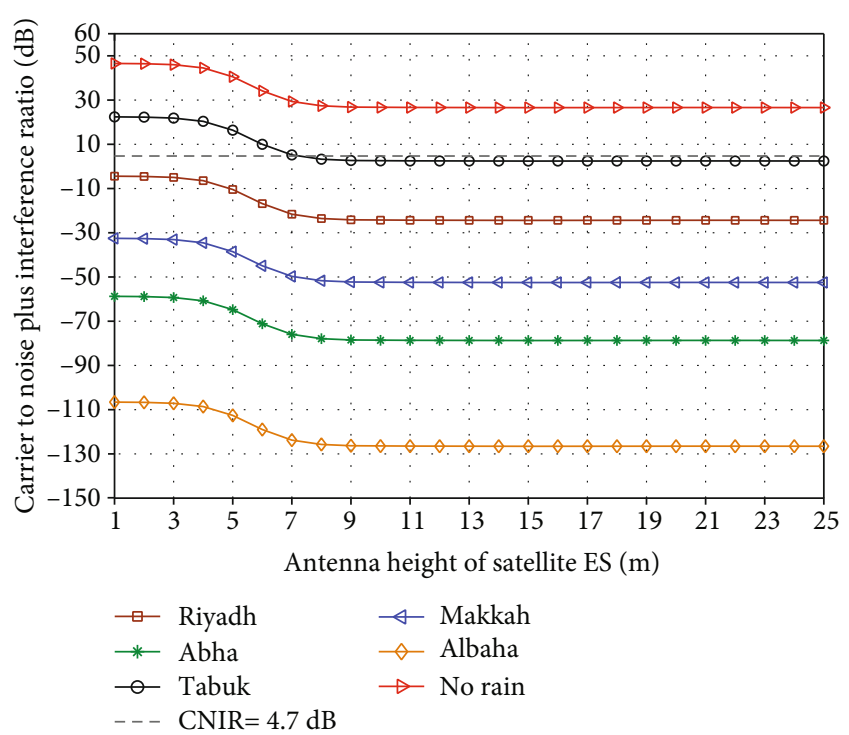

FIgURE 6: The CNIR against ES antenna height (suburban area).

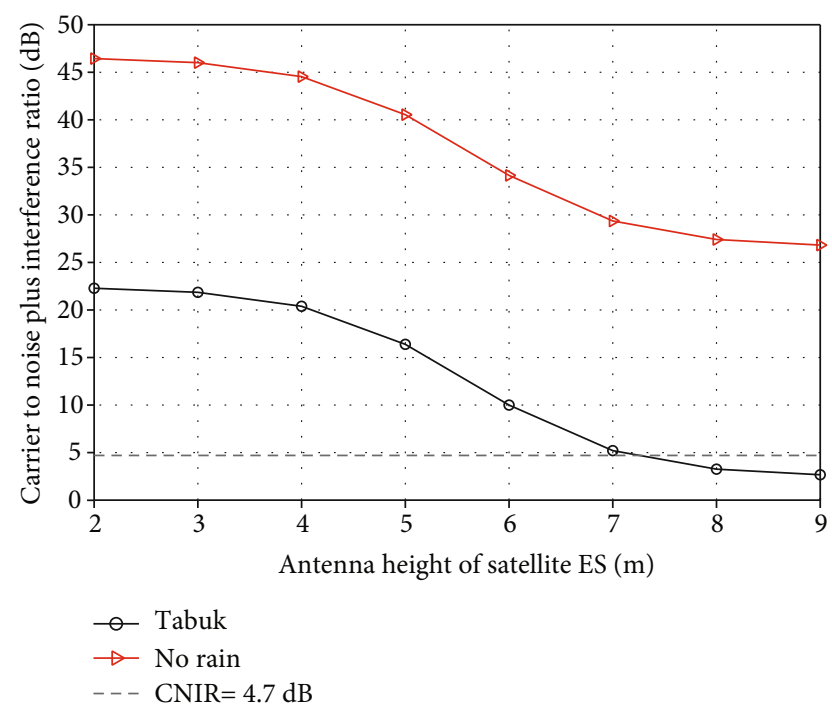

FIgURE 7: Magnification of Figure 6: the CNIR against the ES antenna height in $\mathrm{Al} \mathrm{Bahah} \mathrm{(Suburban} \mathrm{area).}$

changing the antenna height in these two areas is not an efficient technique. However, the DBS system receiver works peacefully in both areas because the required ratio of the CNIR is about 18.9-19.7. That is, it is achieved and greater than the minimum level of $4.7 \mathrm{~dB}$. Note that the receiver sensitivity signal has been adjusted for all selected locations at $-119.566 \mathrm{dBW}$.

Several scenarios have been carried out to investigate the received signal in terms of the CNIR in the five areas of Saudi Arabia for the availability of rain of $R_{0.01}$ of the year and using different heights of the receiver antenna of the DBS system as can be shown in Figures 4 and 5 for the urban and suburban areas, respectively. Figure 4 shows that $\mathrm{Al}$ Bahah is the worst area that suffers from the attenuation of rain; therefore, the CNIR is the lowest level especially for antenna heights between 10 and $20 \mathrm{~m}$. The value of the

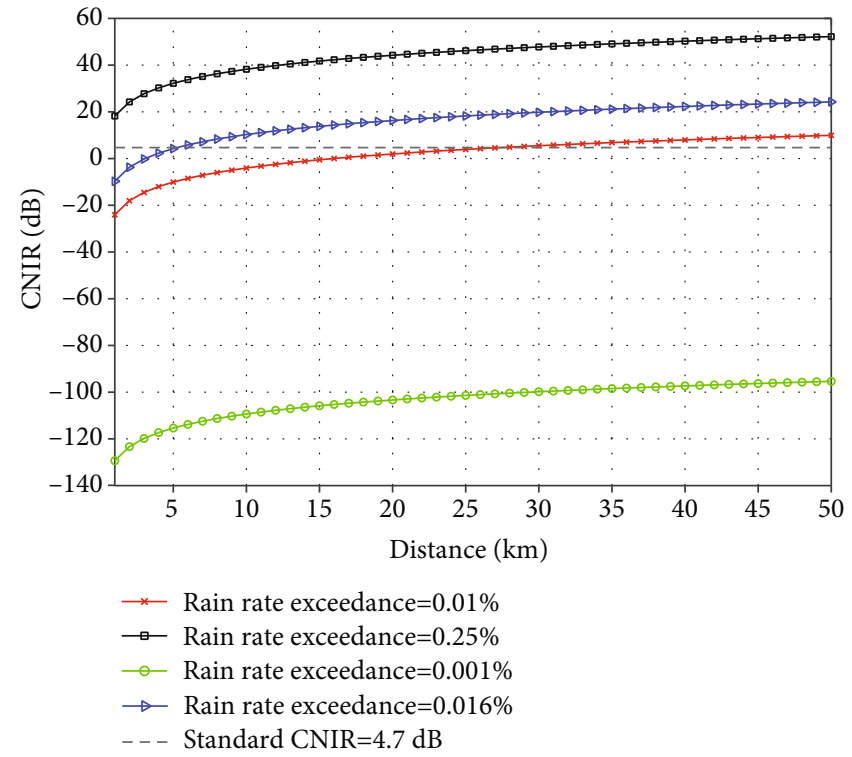

FIgURE 8: The receiver CNIR due to rain in Riyadh.

CNIR is about -110.1 to $-126.3 \mathrm{~dB}$ for the height of $10-$ $20 \mathrm{~m}$, as shown in Figure 6. Also, it can be observed in Figure 4 that before and after the abovementioned heights, the ratio of the CNIR is fixed. The decrease in the CNIR during that height is because as the antenna height of the DBS receiver increases, the interference signal level coming from the fixed wireless system does not face the surrounding objects to block the radiated signal (low clutter loss) in its path so the interference raises and the CNIR will be a low value and then the performance is worse. On the other hand, it can be observed that the Tabuk area does not suffer from interference if the DBS receiver antenna height is lower than $18 \mathrm{~m}$ because the CNIR is larger or at least equal to $4.7 \mathrm{~dB}$. Moreover, the DBS system receiver in the other areas, Riyadh, Makkah, and Abha, negatively works during rain situations due to the degradation in the satellite signal and then the lower value of the CNIR. However, Figure 4 illustrates that the situation of the clear sky condition (no rain) is the best situation and the DBS receiver system can operate in any area because the signal arrives at the DBS receiver with a highly enough CNIR ratio.

Figure 5 illustrates the situation for the five areas under precipitation in the suburban environment. This area is characterized by an open atmosphere more than that of the urban areas. Unlike urban areas, in suburban areas, there are no tall and congested buildings or towers that can block communication signals. Therefore, the interference effect will be high in these areas and this is obvious in Figure 7, in which it is shown that a small increase in the height of the DBS receiver antenna from $4 \mathrm{~m}$ to $8 \mathrm{~m}$ can raise interference and decrease the CNIR by roughly $17 \mathrm{~dB}$. That is, for the same change of antenna height $(4-8 \mathrm{~m})$, as shown in Figure 7 , the value of the CNIR decreases from $20.4 \mathrm{~dB}$ to $3.3 \mathrm{~dB}$ in Tabuk which is the only area that can well operate in this situation. In the case of the antenna height increase by more than $7.3 \mathrm{~m}$, the system will suffer from an acceptable interference and will not work. The former situation is 


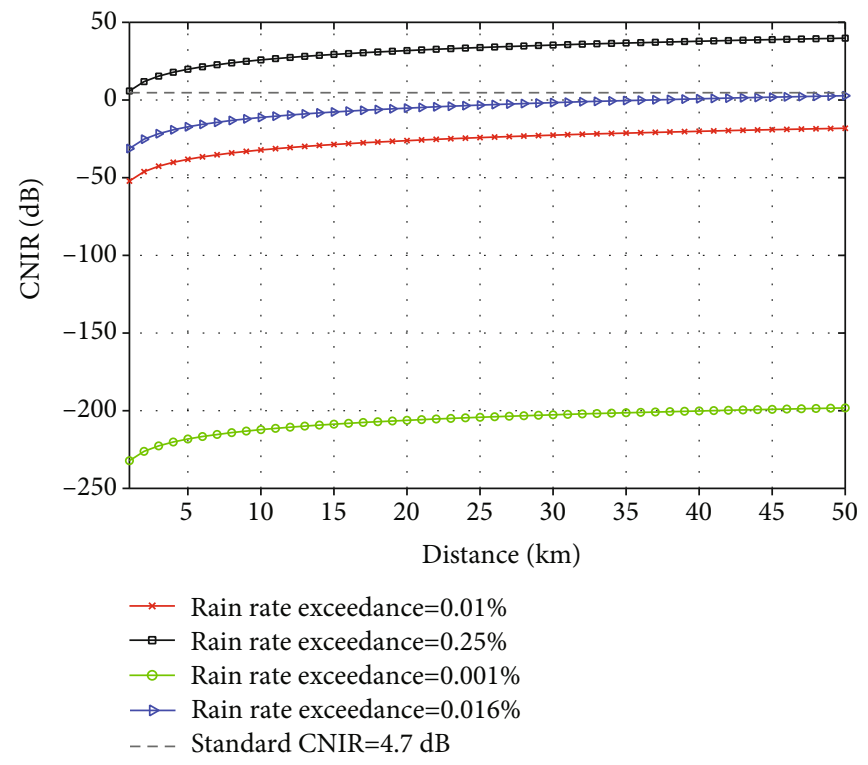

FIgURE 9: The receiver CNIR due to rain in Makkah.

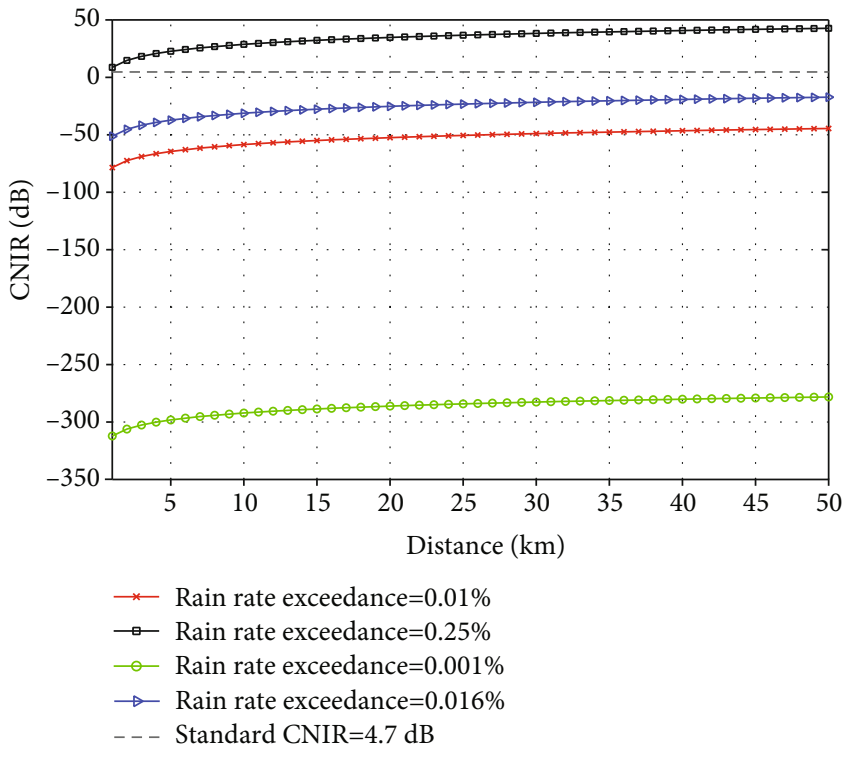

Figure 10: The receiver CNIR due to rain in Abha.

the case for the other areas except Tabuk where the conditions does not allow the DBS system to operate because the CNIR value is smaller than $4.7 \mathrm{~dB}$ even for very low antenna heights. Figure 6 also illustrates that in the no-rain case, the system will work with high performance for all areas.

More values of precipitation unavailability percentage have been considered for this study, the values are 0.25 , 0.001 , and $0.016 \%$ in addition to $0.01 \%$. These conditions have been applied to all the abovementioned geographical areas. In the capital city, Riyadh, as illustrated in Figure 8, the DBS system receiver works with acceptable performance at a rain rate that exceeded by $0.25 \%$ of the year, whereas at rain rates of $0.01 \%$ and $0.016 \%$, the DBS system receiver needs a guard distance of 5 and $24 \mathrm{~km}$, respectively, to oper- ate without the negative effect of interference of the terrestrial fixed service. However, at a rain rate that exceeded by $0.25 \%$ of the year, the DBS system receiver cannot properly operate if the interference or rain mitigation techniques have not been used. It can be noted that the rate of change in the CNIR is about $0-35 \mathrm{~dB}$ within the distance of $1-50 \mathrm{~km}$ for all areas.

In the area of Makkah, as shown in Figure 9, the situation is approximately similar to Riyadh at a rain rate that exceeded by $0.25 \%$ of the year, in which there is no need for a protection distance despite that the CNIR value is higher in Riyadh than in Makkah by approximately $20 \mathrm{~dB}$. However, it is worse than Riyadh for a rain rate more than that percentage. That is, the required minimum protection distance is roughly $50 \mathrm{~km}$ at a rain rate that exceeded by $0.01 \%$, whereas the DBS system receiver cannot work at the other two rain rates, $0.016 \%$ and $0.001 \%$, due to the large decrease in the CNIR value which is caused by the higher rain rate in Makkah than Riyadh.

In Abha and $\mathrm{Al}$ Bahah, the situation is more difficult than that in Riyadh and Makkah due to the high attenuation of rain caused by high rain rates. In both areas (Abha and $\mathrm{Al}$ Bahah), it can be seen in Figures 10 and 11 that the DBS system receiver can only peacefully operate at a rain rate that exceeded by $0.25 \%$ of the year. Whereas, the other exceedance of rain rates $0.01 \%, 0.016 \%$, and $0.001 \%$ makes the system in an outage condition due to high negative CNIR values that come from a high rain rate specifically in the $\mathrm{Al}$ Bahah area. For example, at a rate of $0.01 \%$, the CNIR is -18 and $-55 \mathrm{~dB}$ at a separation distance of $50 \mathrm{~km}$ between the DBS receiver and the fixed wireless system; the late values become much lower at the $50 \mathrm{~km}$ distance between the two abovementioned systems in both areas.

For the Tabuk area, the DBS system receiver operates better than that in the other areas due to the fact that the CNIR value represents the best among CNIRs in other areas for all situations. Figure 12 shows that the DBS receiver will 


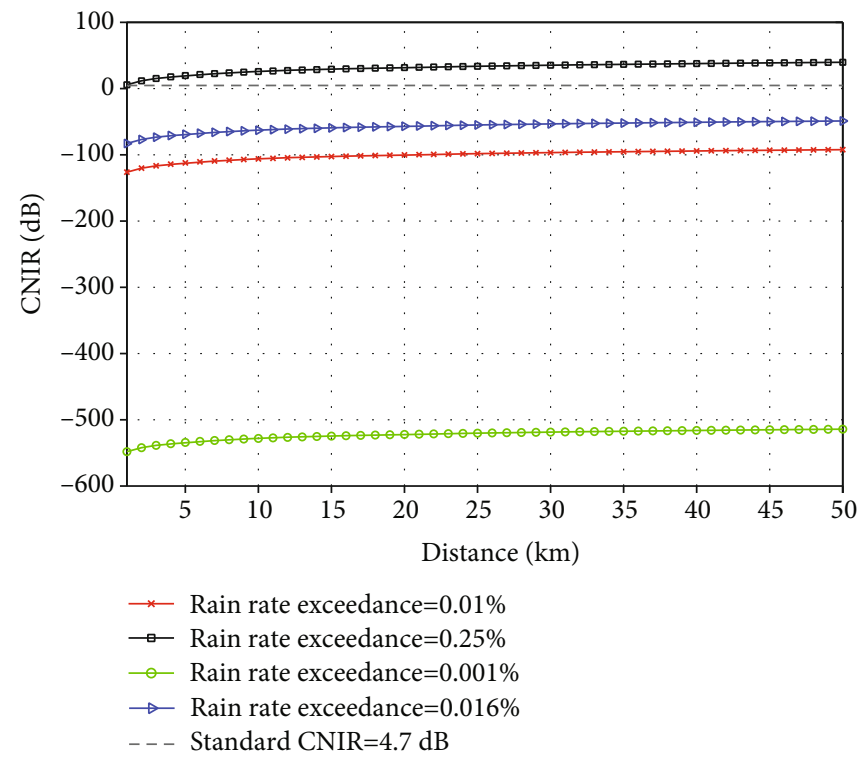

FIgURE 11: The receiver CNIR due to rain in Al Bahah.

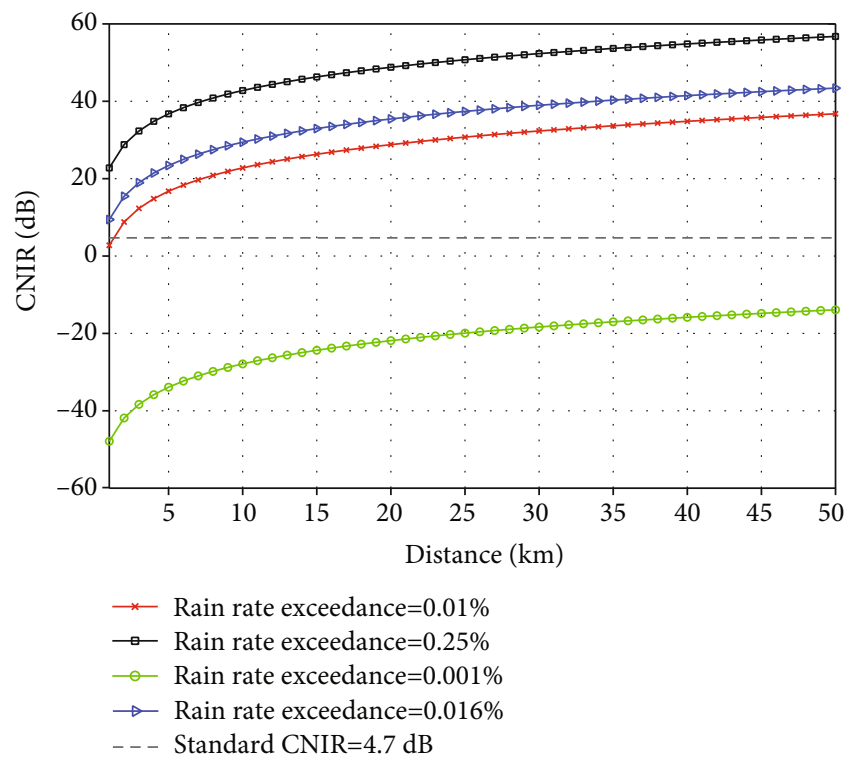

FIgURE 12: The receiver CNIR due to rain in Tabuk.

operate under a rain rate exceedance of $0.25 \%$ and $0.01 \%$ with no protection distance to avoid interference from the terrestrial fixed wireless system. While for a rain rate exceedance of $0.016 \%$ for both systems to work properly, there is a need to make a separation distance of $1.3 \mathrm{~km}$ between the DBS and fixed service. However, the system will absolutely not operate for $0.001 \%$ without using coordination techniques to prevent interference from the fixed service or techniques to raise the power received by the DBS receiver.

Moreover, the possible interference power that can be received from the terrestrial FS interferer is partially dependent on the DBS ES antenna gain in the direction of the terrestrial FS interferer. This effect can be termed as the off-axis angle or the off-boresight angle [41]. The off-axis angle is

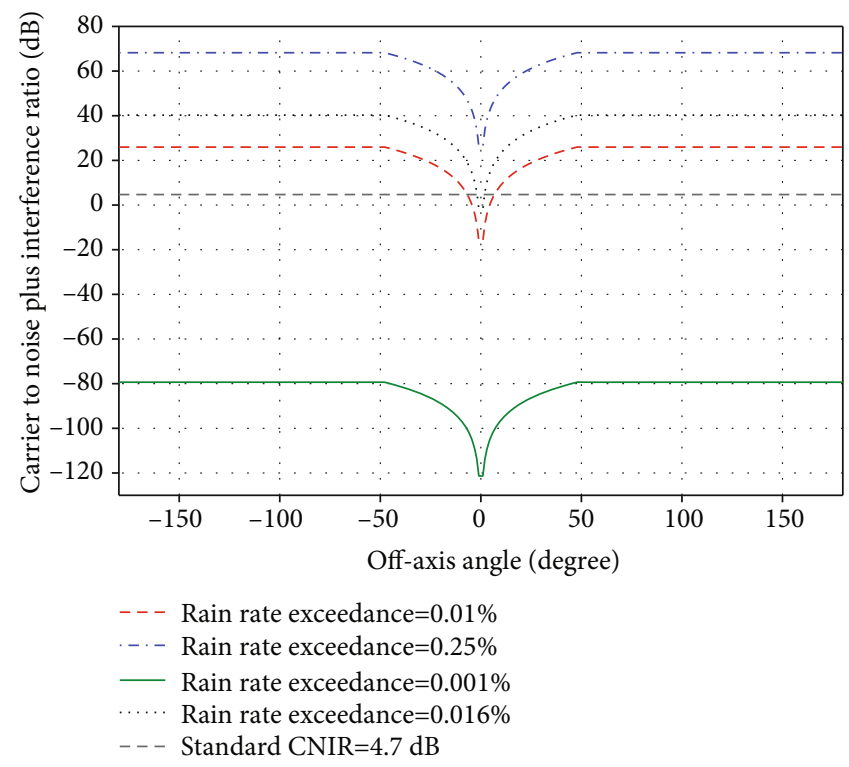

FIGURE 13: CNIR vs. the off-axis angle of Riyadh at $10 \mathrm{~km}$ between the FS and DBS receiver.

defined as the angle between the interference axis and the DBS ES antenna main lobe direction [41]. Figures 13-17 show the effect of the off-axis angle between the DBS satellite Earth station and the FS transmitter that is assumed to be $10 \mathrm{~km}$ apart.

It is observed in Figures 13-17 that there is a significant impact of the off-axis angle particularly for the low-rain rate areas. The values of the CNIR for all areas increase as the offaxis angle increases till it reaches $48^{\circ}$, and then, CNIR values stay constant according to the satellite antenna pattern. In Figure 13, the curves show that the two systems (FS and DBS ES) can operate with no interference harmful for a rain exceedance of. $25 \%$ for all off-axis angles, whereas for rain rates of $0.016 \%$ and $0.01 \%$, the two systems cannot work 


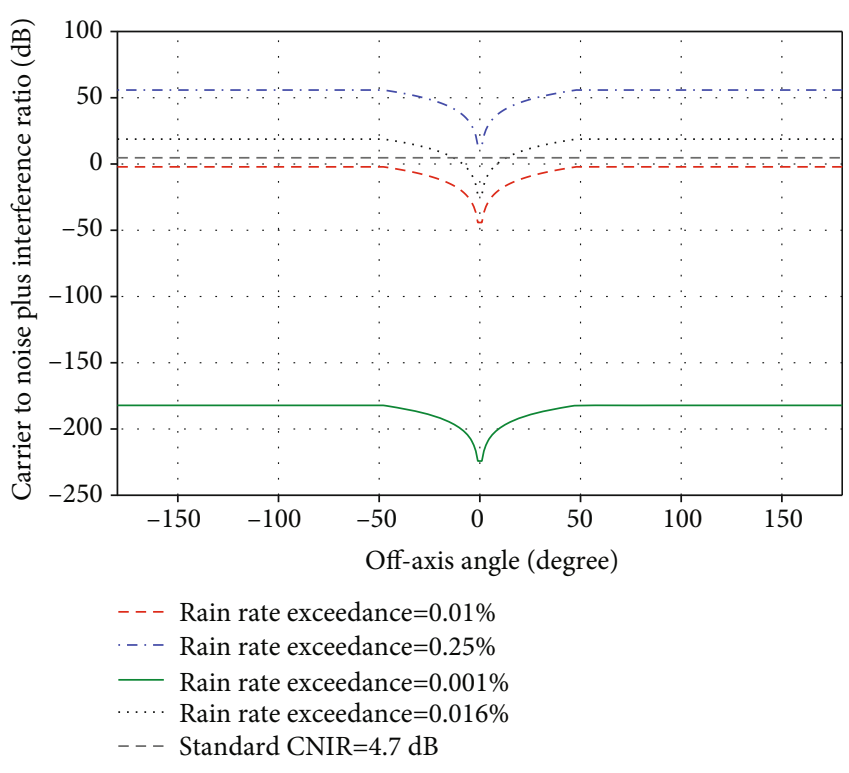

Figure 14: CNIR vs. the off-axis angle of Makkah at $10 \mathrm{~km}$ between the FS and DBS receiver.

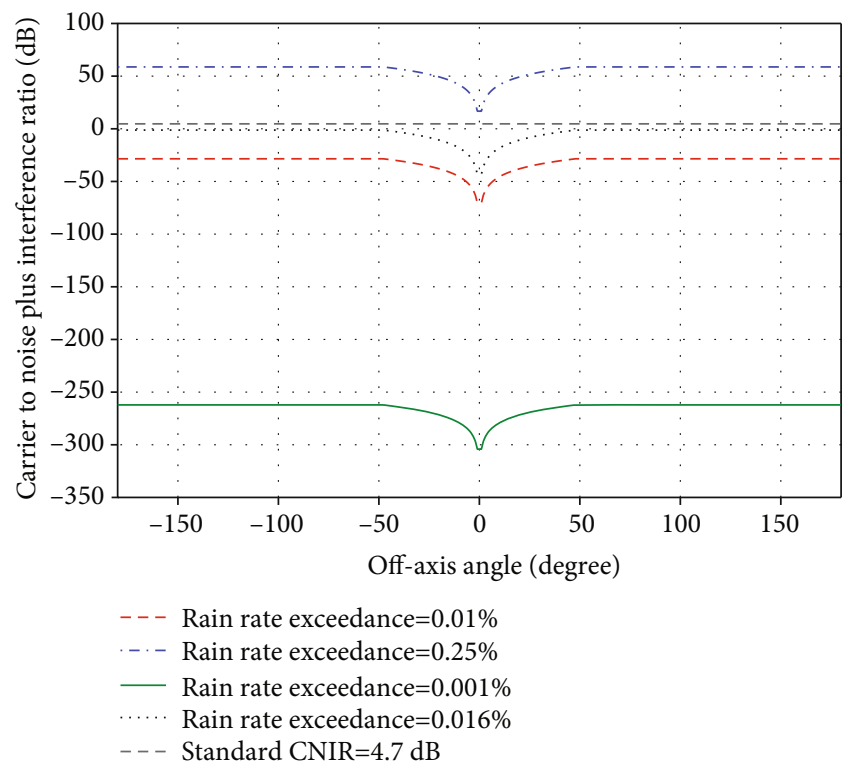

Figure 15: CNIR vs. the off-axis angle of Abha at $10 \mathrm{~km}$ between the FS and DBS receiver.

together if the off-axis angles are less than $\mp 1.58^{\circ}$ and $\mp 6.77^{\circ}$. Also, in the Makkah area, an angle of $\mp 13.1^{\circ}$ between the FS and DBS ES is required for a rain rate exceedance of $0.016 \%$ for the concurrent operation, while the systems cannot simultaneously function if the rain rate is heavier (with an exceedance of 0.01 and $0.001 \%$ ). The situation in Abha and Al Bahah seems comparable regarding the off-axis influence, and the frequency sharing is only possible for the lowest rain rates $(0.25 \%$ exceedance) while it is impossible for the other rates taking into account the difference in values of the CNIR. Finally, Tabuk seems to be the best area for the two systems to simultaneously work with no considering offaxis coordination at $0.25 \%, 0.016 \%$, and $0.01 \%$ exceedance;

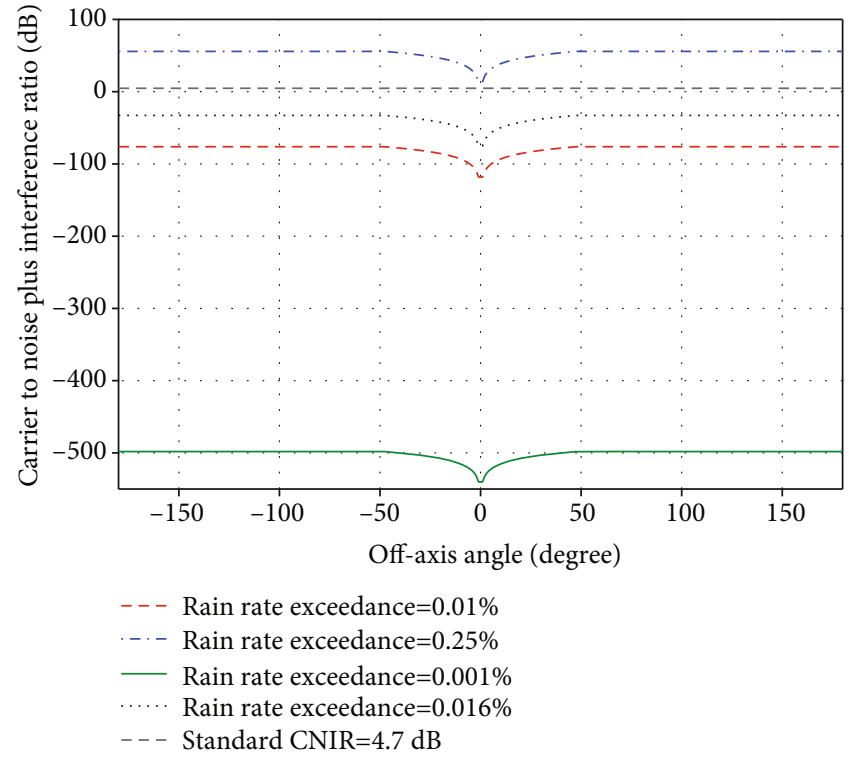

Figure 16: CNIR vs. the off-axis angle of $\mathrm{Al} \mathrm{Bahah} \mathrm{at} 10 \mathrm{~km}$ between the FS and DBS receiver.

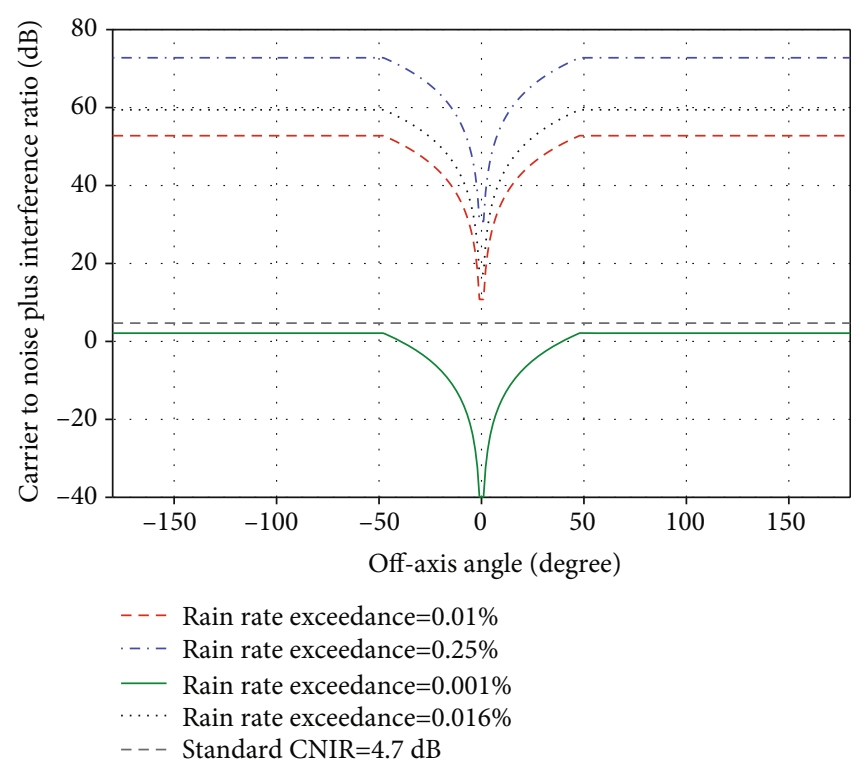

FIgUre 17: CNIR vs. the off-axis angle of Tabuk at $10 \mathrm{~km}$ between the FS and DBS receiver.

however, at an exceedance of $0.001 \%$, the concurrent work is not feasible.

From the abovementioned analysis, it can be concluded that coordination using an off-axis angle makes a difference in the case of medium rain rates $(0.016$ and $0.01 \%)$ as in Riyadh and Makkah as shown in Table 4 which summarizes the effect of the off-axis angle variation.

The authors believe that the results predicted in this paper can replace or reduce the requirements for physical measurements due to the fact that the results depend on real and measured rainfall data and the simulation method is authorized by the ITU-R as a global body of communication organizing [40]. In addition, this model [40] has been widely 
TABLE 4: The effect of the off-axis angle.

\begin{tabular}{lccccc}
\hline Exceedance & Tabuk & Riyadh & Makkah & Abha & Al Bahah \\
\hline $0.25 \%$ & $\begin{array}{c}\text { All } \\
\text { angles }\end{array}$ & $\begin{array}{c}\text { All } \\
\text { angles }\end{array}$ & $\begin{array}{c}\text { All } \\
\text { angles }\end{array}$ & $\begin{array}{c}\text { All } \\
\text { angles }\end{array}$ & $\begin{array}{c}\text { All } \\
\text { angles }\end{array}$ \\
$0.016 \%$ & $\begin{array}{c}\text { All } \\
\text { angles }\end{array}$ & $>\mp 1.58^{\circ}$ & $<\mp 13.1^{\circ}$ & No & No \\
$0.01 \%$ & $\begin{array}{c}\text { All } \\
\text { angles }\end{array}$ & $>\mp 6.77^{\circ}$ & No & No & No \\
$0.001 \%$ & No & No & No & No & No \\
\hline
\end{tabular}

used by many researchers over the world such as in [42-44], in which the results are of global acceptability.

\section{Conclusion}

This paper introduced significant results on the operation of the DBS receiver under the influence of precipitation and interference from the FS service at the K-frequency band. The results showed that the rate of change in the CNIR is about $0-35 \mathrm{~dB}$ within the distance of $1-50 \mathrm{~km}$ for all areas under the study. The conditions in the Al Bahah area represent the most worse area in the entire region, whereas Tabuk represents the best area that can work properly in most cases under rain rates with less restriction due to the lower and higher values of the CNIR of the DBS receiver in both areas. Similar restrictions on the CNIR, separation distance, frequency separation, and so on can be also applied to different countries with similar precipitation circumstances. Modifying the off-axis angle to coordinate the DBS and FS systems can reduce the interference from the FS system especially when the CNIR threshold is within the off-axis angle varying range as in Riyadh and Makkah areas. Several techniques also can be suggested to use in critical situations under high rainfall such as automatic gain control (AGC) and/or adaptive modulation techniques. In addition, the interference coming from the wireless terrestrial system to the DBS receiver can be avoided by adjusting the feasible required physical distance.

\section{Data Availability}

The rainfall data used to support the findings of this study are included within the article and cited references.

\section{Conflicts of Interest}

The authors declare that they have no conflicts of interest.

\section{References}

[1] L. Castanet, A. Bolea-Alamañac, and M. Bousque, "Interference and fade mitigation techniques for $\mathrm{Ka}$ and $\mathrm{Q} / \mathrm{V}$ band satellite communication systems," in Proceedings of the 2nd International Workshop of COST Action, vol. 280, pp. 1-8, Noordwijk, The Netherlands, 2003.

[2] Z. A. Shamsan, "Rainfall and diffraction modeling for millimeter-wave wireless fixed systems," IEEE Access, vol. 8, pp. 212961-212978, 2020.
[3] Z. A. Shamsan, "38-GHz point-to-point wireless radio link prediction based on propagation and terrain path profile in Riyadh," University Politehnica Of Bucharest Scientific Bulletin, Series C-Electrical Engineering And Computer Science, vol. 80, no. 1, pp. 121-134, 2018.

[4] W. A. Hasan, S. K. A. Rahim, Z. A. Shamsan, K. G. Tan, and A. W. Reza, "Potential interference and rain attenuation at 21.4-22 GHz downlink broadcasting satellite signals," International Journal of Electronics, vol. 98, no. 12, pp. 1721-1731, 2011.

[5] T. T. Ha, Digital Satellite Communications, Macmillan, New York, 1986.

[6] M. D. Gallagher, Interference Pprotection Ccriteria Phase 1Ccompilation from Existing Sources, Assistant secretary for communications and information, 2005.

[7] Z. A. Shamsan, A. Alburaih, F. Alyahya, and S. Alshalawi, "Effects of interference and precipitation on the $21.4-22 \mathrm{GHz}$ downlink direct broadcasting satellite in Saudi Arabia," in 2017 IEEE 15th Student Conference on Research and Development (SCOReD), pp. 440-444, Malaysia, 2017.

[8] A. D. Panagopoulos, P. D. Arapoglou, G. E. Chatzarakis, J. D. Kanellopoulos, and P. G. Cottis, "Coexistence of the broadcasting satellite service with fixed service systems in frequency bands above $10 \mathrm{GHz}$," IEEE Transactions on Broadcasting, vol. 52, no. 1, pp. 100-107, 2006.

[9] H. K. Son and Y. J. Chong, "Coexistence of 5G system with fixed satellite service earth station in the $3.8 \mathrm{GHz}$ band," in 2018 international conference on information and communication technology convergence (ICTC), pp. 1070-1073, Jeju, Korea (South), 2018.

[10] E. Lagunas, C. G. Tsinos, S. K. Sharma, and S. Chatzinotas, "5G cellular and fixed satellite service spectrum coexistence in Cband," IEEE Access, vol. 8, pp. 72078-72094, 2020.

[11] S. K. Sharma, S. Maleki, S. Chatzinotas, J. Grotz, and B. Ottersten, "Implementation issues of cognitive radio techniques for Ka-band (17.7-19.7 GHz) SatComs," in 2014 7th Advanced Satellite Multimedia Systems Conference and the 13th IEEE Signal Processing for Space Communications Workshop (ASMS/SPSC), pp. 241-248, Livorno, Italy, September 2014.

[12] A. Khawar, I. Ahmad, and A. I. Sulyman, "Spectrum sharing between small cells and satellites: opportunities and challenges," in 2015 IEEE International Conference on Communication Workshop (ICCW), pp. 1600-1605, London, UK, June 2015.

[13] A. Guidotti, V. Icolari, D. Tarchi et al., "Spectrum awareness and exploitation for cognitive radio satellite communications," in 2015 IEEE European conference on networks and communications (EuCNC), pp. 16-20, Paris, France, June 2015.

[14] W. Tang, P. Thompson, and B. Evans, "Frequency sharing between satellite and terrestrial systems in the Ka band: a database approach," in 2015 IEEE International Conference on Communications (ICC), pp. 867-872, London, UK, June 2015.

[15] D. S. Oh, S. M. Lee, D. S. Ahn, and S. Kim, "A study on the separation distance for frequency sharing between gso network and terrestrial network in Ka band," in VTC spring 2008IEEE Vehicular Technology Conference, pp. 2967-2971, Marina Bay, Singapore, May 2008.

[16] M. Höyhtyä, "Frequency sharing between FSS and BSS satellites in the 17.3-18.4 GHz band," in 2015 Advances in wireless and optical communications (RTUWO), pp. 176-179, Riga, Latvia, November 2015. 
[17] J. M. Park, D. S. Oh, and D. C. Park, "Coexistence of mobilesatellite service system with mobile service system in shared frequency bands," IEEE Transactions on Consumer Electronics, vol. 55, no. 3, pp. 1051-1055, 2009.

[18] M. Irfan and A. Qadir, "Spectrum sharing studies in C band between IMT2000 (WIMAX) \& satellite networks," in 2009 IEEE 9th Malaysia International Conference on Communications (MICC), pp. 497-500, Kuala Lumpur, Malaysia, December 2009.

[19] ITU-R BO, 1297, Protection Ratios to Be Used for Planning Purposes in the Revision of the Appendices 30 (Orb-85) and 30a (Orb-88) Plans of the Radio Regulations in Regions 1 and 3, ITU, Geneva, 1997.

[20] N. S. Accuille, Advanced Satellite Engineering and Applications, John Wiley \& Sons, New York, 3rd Ed. edition, 1999.

[21] D. Roddy, Satellite Communications, McGraw-Hill, New York, 3rd Edn edition, 2001.

[22] S. N. Livieratos and J. D. Kanellopoulos, "Prediction of the degradation of the carrier-to-noise plus interference ratio concerning a site diversity system suffering from differential rain attenuation," Radio Science, vol. 37, no. 5, pp. 18-1-1813, 2002.

[23] W. M. Wiltshire, M. D. Nilsson, and F. B. Campbell, Application for Authorization to Launch and Operate direcTV 15, Federal Communications Commission, Washington, 2004.

[24] ITU-R S, “1328-4 recommendation: satellite system characteristics to be considered in frequency sharing analyses within the fixed-satellite service," 2002.

[25] C. I. Kourogiorgas, P. D. Arapoglou, and A. D. Panagopoulos, "Statistical characterization of adjacent satellite interference for earth stations on mobile platforms operating at $\mathrm{Ku}$ and Ka bands," IEEE Wireless Communications Letters, vol. 4, no. 1, pp. 82-85, 2015.

[26] K. Sung, H. Haas, and S. McLaughlin, "A semianalytical PDF of downlink SINR for femtocell networks," Journal of Wireless Com Network, vol. 2010, no. 1, article 256370, pp. 1-9, 2010.

[27] D. Gesbert, M. Shafi, da-shan Shiu, P. J. Smith, and A. Naguib, "From theory to practice: an overview of MIMO space-time coded wireless systems," IEEE Journal on Selected Areas in Communications, vol. 21, no. 3, pp. 281-302, 2003.

[28] R. Blum, "MIMO capacity with interference," IEEE Journal on Selected Areas in Communications, vol. 21, no. 5, pp. 793-801, 2003.

[29] K. Cumanan, R. Zhang, and S. Lambotharan, “A new design paradigm for mimo cognitive radio with primary user rate constraint," IEEE Communications Letters, vol. 16, no. 5, pp. 706-709, 2012.

[30] A. Alabbasi, Z. Rezki, and B. Shihada, "Energy efficiency and SINR maximization beamformers for spectrum sharing with sensing information," IEEE Transactions on Wireless Communications, vol. 13, no. 9, pp. 5095-5106, 2014.

[31] A. M. al-Samman, M. H. Azmi, Y. A. al-Gumaei et al., "Millimeter wave propagation measurements and characteristics for 5G system," Applied Sciences, vol. 10, no. 1, p. 335, 2020.

[32] A. al-Saman, M. Mohamed, M. Cheffena, M. Azmi, and T. Rahman, "Performance of full-duplex wireless back-haul link under rain effects using E-band $73 \mathrm{GHz}$ and $83 \mathrm{GHz}$ in tropical area," Applied Sciences, vol. 10, no. 17, p. 6138, 2020.

[33] A. M. Al-Saman, M. Cheffena, M. Mohamed, M. H. Azmi, and Y. Ai, "Statistical analysis of rain at millimeter waves in tropical area," IEEE Access, vol. 8, pp. 51044-51061, 2020.
[34] A. M. Al-Samman, M. Mohamed, Y. Ai, M. Cheffena, M. H. Azmi, and T. A. Rahman, "Rain attenuation measurements and analysis at $73 \mathrm{GHz}$ E-band link in tropical region," IEEE Communications Letters, vol. 24, no. 7, pp. 1368-1372, 2020.

[35] A. A. Ali, M. A. Alhaider, and M. A. Shatila, "Rain map for radiowave propagation design in Saudi Arabia," International Journal of Infrared and Millimeter Waves, vol. 7, no. 11, pp. 1777-1793, 1986.

[36] ITU-R F, 2471 Recommendation: Sharing and Compatibility Studies of HAPS Systems in the Fixed Service in the 21.4-22 GHz Frequency Range for Region 2, ITU, Geneva, 2019.

[37] Z. A. Shamsan, T. A. Rahman, and A. M. al-Hetar, "Pointpoint fixed wireless and broadcasting services coexistence with IMT-advanced system," Progress In Electromagnetics Research, PIER, vol. 122, pp. 537-555, 2012.

[38] Z. A. Shamsan, "Bandwidth overlap factor for feasible coexistence of LTE-A and point to multipoint LMDS systems," Wireless Personal Communications, vol. 97, no. 2, pp. 20172035, 2017.

[39] Z. A. Shamsan, "Clear air and precipitation millimeter-wave point-to-point wireless link prediction based on terrain path profile in semi-arid climate," Journal of Telecommunication, Electronic and Computer Engineering (JTEC), vol. 10, no. 2-7, pp. 17-21, 2018.

[40] ITU-R P, 452-11 Recommendation: Prediction Procedure for the Evaluation of Microwave Interference between Stations on the Surface of the Earth at Frequencies above about $0.7 \mathrm{GHz}$, Geneva, ITU, 2003.

[41] ITU-R S, 465-6, Reference Radiation Pattern for Earth Station Antennas in the Fixed-Satellite Service for Use in Coordination and Interference Assessment in the Frequency Range from 2 to $31 \mathrm{GHz}, 2010$.

[42] H. S. Jo, H. G. Yoon, J. Lim, W. G. Chung, J. G. Yook, and H. K. Park, "The coexistence of OFDM-based systems beyond 3G with fixed service microwave systems," Journal of Communications and Networks, vol. 8, no. 2, pp. 187-193, 2006.

[43] W. G. Chung, H. S. Jo, H. G. Yoon, J. W. Lim, J. G. Yook, and H. K. Park, "Advanced MCL method for sharing analysis of IMT-advanced systems," Electronics Letters, vol. 42, no. 21, pp. 1234-1235, 2006.

[44] M. Höyhtyä, M. Majanen, M. Hoppari et al., "Licensed shared access field trial and a testbed for satellite-terrestrial communication including research directions for 5G and beyond," International Journal of Satellite Communications and Networking, vol. 39, no. 4, pp. 455-472, 2021. 